\title{
Impact of Drilling Operations on Lunar Volatiles Capture: Thermal Vacuum Tests
}

\author{
Julie Kleinhenz \\ NASA Glenn Research Center, Cleveland, OH 44135 \\ Gale Paulsen ${ }^{2}$, Kris Zacny ${ }^{3}$ \\ Honeybee Robotics Spacecraft Mechanisms Corporation, Pasadena, CA, 91103 \\ and \\ Jim Smith ${ }^{4}$ \\ NASA Kennedy Space Center, Florida, 32899
}

In Situ Resource Utilization (ISRU) enables future planetary exploration by using local resources to supply mission consumables. This idea of 'living off the land' has the potential to reduce mission cost and risk. On the moon, water has been identified as a potential resource (for life support or propellant) at the lunar poles, where it exists as ice in the subsurface. However, the depth and content of this resource has yet to be confirmed on the ground; only remote detection data exists.

The upcoming Resource Prospector mission (RP) will 'ground-truth' the water using a rover, drill, and the RESOLVE science package. As the 2020 planned mission date nears, component level hardware is being tested in relevant lunar conditions (thermal vacuum). In August 2014 a series of drilling tests were performed using the Honeybee Robotics Lunar Prospecting Drill inside a 'dirty' thermal vacuum chamber at the NASA Glenn Research Center. The drill used a unique auger design to capture and retain the lunar regolith simulant. The goal of these tests was to investigate volatiles (water) loss during drilling and sample transfer to a sample crucible in order to validate this regolith sampling method.

Twelve soil samples were captured over the course of two tests at pressures of $10^{-5}$ Torr and ambient temperatures between $-80{ }^{\circ} \mathrm{C}$ to $-20{ }^{\circ} \mathrm{C}$. Each sample was obtained from a depth of $40 \mathrm{~cm}$ to $50 \mathrm{~cm}$ within a cryogenically frozen bed of NU-LHT-3M lunar regolith simulant doped with 5 wt \% water. Upon acquisition, each sample was transferred and hermetically sealed inside a crucible. The samples were later baked out to determine water wt $\%$ and in turn volatile loss by following ASTM standard practices. Of the twelve tests, four sealed properly and lost an average of $30 \%$ of their available water during drilling and transfer. The variability in the results correlated well with ambient temperature (lower the temperature lower volatiles loss) and the trend agreed with the sublimation rates for the same temperature. Moisture retention also correlated with quantity of sample: a larger amount of material resulted in less water loss. The drilling process took an average of 10 minutes to capture and transfer each sample. The drilling power was approximately 20 Watt with a Weight on Bit of approximately $30 \mathrm{~N}$. The bit temperature indicated little heat input into formation during the drilling process.

\footnotetext{
${ }^{1}$ Research Engineer, Propellants and Propulsion Branch, MS 301-3 21000 Brookpark Road, Cleveland, OH 44135, Senior Member.

${ }^{2}$ Senior Systems Engineer, 398 W Washington Blvd, Suite 200, Honeybee Robotics, Pasadena, CA, 91103.

${ }^{3}$ Director, Exploration Technology Group, 398 W Washington Blvd, Suite 200, Honeybee Robotics, Pasadena, CA, 91103, Senior Member

${ }^{4}$ RESOLVE Lead Systems Engineer, Structures \& Mechanisms Design Branch, NE-M2, NASA Kennedy Space Center, FL 32899.
}

American Institute of Aeronautics and Astronautics 


\section{Nomenclature}

$\begin{array}{ll}G N_{2} & =\text { Gaseous Nitrogen } \\ I S R U & =\text { In-Situ Resource Utilization } \\ \text { LAVA } & =\text { Lunar Advanced Volatiles Analysis } \\ \text { LCROSS } & =\text { Lunar Crater Observation and Sensing Satellite } \\ L N_{2} & =\text { Liquid Nitrogen } \\ M E R & =\text { Mars Exploration Rover } \\ \text { NIRVSS } & =\text { Near InfraRed Volatiles Spectrometer Subsystem } \\ \text { NSS } & =\text { Neutron Spectrometer Subsystem } \\ \text { OVEN } & =\text { Oxygen and Volatile Extraction Node } \\ R A T & =\text { Rock Abrasion Tool } \\ R E S O L V E & =\text { Regolith and Environment Science and Oxygen \& Lunar Volatile Extraction } \\ R G A & =\text { Residual Gas Analyzer } \\ R P & =\text { Resource Prospector } \\ S C M & =\text { Sample Capture Mechanism } \\ V F 13 & =\text { Vacuum Facility \#13 } \\ W O B & =\text { Weight On Bit }\end{array}$

\section{Introduction}

$\mathbf{I}^{\mathrm{N}}$

Situ Resource Utilization (ISRU) enables future planetary exploration by using local resources to supply mission consumables for life support or propellant. This idea of 'living off the land' has the potential to reduce mission cost and risk. On the moon, water has been identified as a potential resource at the lunar poles where it exists as ice in the subsurface. However, the depth and content of this resource has yet to be confirmed on the ground; only remote detection data exists ${ }^{1,2}$.

In order to 'ground-truth' and demonstrate ISRU capabilities, NASA is developing the Resource Prospector mission (RP) ${ }^{3}$. The rover mounted RESOLVE (Regolith and Environment Science and Oxygen \& Lunar Volatile Extraction) science package includes a drill, a neutron spectrometer (the Neutron Spectrometer Subsystem (NSS)), a nearinfrared spectrometer (the Near InfraRed Volatiles Spectrometer Subsystem (NIRVSS)), a reactor (the Oxygen and Volatile Extraction Node (OVEN)), and a gas chromatograph/mass spectrometer (The Lunar Advanced Volatiles Analysis (LAVA) Subsystem). Using this combination of instruments RESOLVE can identify the presence of surface and subsurface volatiles in the lunar regolith.

As the 2020 planned mission date nears, component level hardware is being tested in relevant lunar conditions (thermal vacuum). In September 2013 the NIRVSS was tested inside the Vacuum Facility 13 (VF13) 'dirty' thermal vacuum chamber at the NASA Glenn Research Center ${ }^{4}$. During these tests an $1 \mathrm{~m}$ auger was used to drill into a frozen bin of lunar regolith simulant while the NIRVSS examined volatiles release from the soil cuttings pile. These tests provided valuable information about the capabilities and detection limits of the instrument. However, the auger system used in these tests was not flight applicable.

In August 2014 a more flight-like drill concept was tested in the VF13 chamber. The Honeybee Robotics Lunar Prospecting Drill ${ }^{5}$ uses a unique auger design to capture and retain the lunar regolith on the flights. The goal of these thermal vacuum tests was to investigate volatiles loss from the soil during drilling and sample transfer in order to validate the auger based regolith sampling method. The lunar soil simulant was doped with $5 \mathrm{wt} \%$ water to match the water content detected at the lunar poles from LCROSS ${ }^{2}$, and chilled to cryogenic conditions $\left(-130^{\circ} \mathrm{C}\right)$. Tests were performed in $10^{-5}$ Torr vacuum.

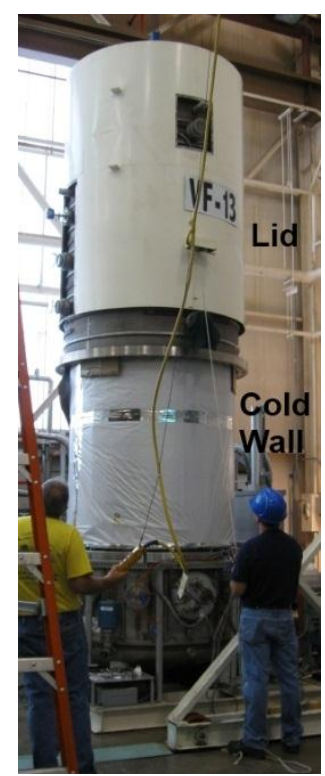

Figure 1: The VF13 chamber with the lid being lowered over the cold wall.

Once the auger captured the soil sample, it was transferred to specially designed sample capture mechanisms (SCM). The SCM was hermetically sealed using remote actuators, upon sample delivery. The soil samples were then baked out by following ASTM standard practices to determine volatile loss. 


\section{Hardware and Procedures}

\section{A. Facility}

The thermal vacuum facility, called VF-13, is a vertical cylindrical chamber with an internal volume of $6.35 \mathrm{~m}^{3}$. The bulk of the volume is within the removable $2.52 \mathrm{~m}$ tall by $1.5 \mathrm{~m}$ diameter lid. A removable cold wall that fits inside this lid (inner diameter with cold wall is $1.35 \mathrm{~m}$ ) can be used for tests requiring a thermal vacuum. Figure 1 shows the lid as it is being lowered over top of the cold wall. The cold wall is composed of two semi-circular sections, each supplied with its own liquid nitrogen feed. These sections can be controlled separately to mimic the severe temperature gradients on the lunar surface. For the tests discussed here, the two halves were maintained at full liquid nitrogen temperature. The fixed base of VF-13 (shown in Fig. 2 without the lid) is $1.08 \mathrm{~m}$ deep and accommodates all the electrical, mechanical, and gas feed-throughs. Four different types of pumps can be used sequentially to achieve a pressure of down to $10^{-6}$ Torr. Liquid nitrogen is plumbed to the facility to accomplish cryogenic cooling of the simulant bin and the removable cold wall.

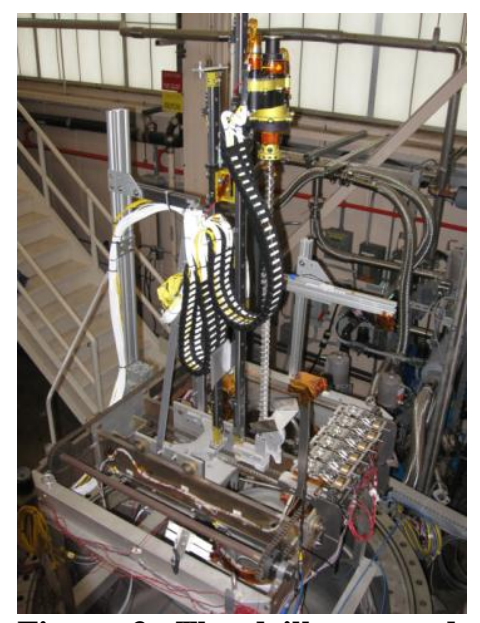

Figure 3: The drill mounted on the translation stage in the chamber. The sample collection mechanism are on the right.
The regolith simulant was contained in a cylindrical aluminum bin $1.2 \mathrm{~m}$ tall with an inner diameter of $0.278 \mathrm{~m}$. The bin height accommodates a $1 \mathrm{~m}$ long drill, and the diameter permits multiple drill holes while keeping heat transfer time (chill down) to a reasonable time frame. The simulant is cooled using liquid nitrogen coolant loops (Fig. 2) clamped to the outside of the bin. Three feed-through ports at various heights along the drill tube accommodate thermocouple probes. Each probe can support five type-T thermocouples which are embedded in the soil at different radial positions, for a total of 15 thermocouples. These thermocouples are embedded in the soil as the bin is filled, and the simulant is compacted on top of them. For this test, only 11 thermocouple probes were used to avoid interference with the drill.

A translation table (Fig. 3) is also available for use in the facility. Research hardware, in this case the drill, is mounted to the trolley. Using remotely actuated stepper motors and chain drives, the trolley can be moved in two dimensions while at thermal vacuum conditions. This gives access to the entire surface of the soil bed so that multiple drill holes can be accomplished in a single test. Given the time involved in the soil preparation and significant cooling time of the soil, this is a valuable feature.

\section{B. Drill}

The Lunar Prospector Drill is based on the Icebreaker drill which was developed for penetrating ice and ice cemented ground on the surface of Mars ${ }^{5,6}$. The major difference between the two systems is that the lunar version of the drill does not have to adhere to the stringent Martian planetary protection protocols. To enable testing at extreme Lunar vacuum levels and cold temperatures, critical drill components were either replaced or upgraded. Lubrication in gearboxes was replaced with dry lube, heaters with embedded thermocouples for thermal control purposes were placed on actuators and Z-stage carriages, and all cabling was replaced.

The drill supports a $100 \mathrm{~cm}$ long, $2.5 \mathrm{~cm}$ diameter auger which is designed to capture a sample on the lowest 10 $\mathrm{cm}$ section of the auger. This section has flutes which are deep and placed at low pitch in a geometry ideal for retaining of granular material. The geometry of the upper section flutes are shallow and with higher pitch which is best suited for efficient cuttings transport. The approach to drilling and sample capture is called 'bite' sampling (or peck drilling in machine shop terminology), which involves progressive drilling and sample capture in $10 \mathrm{~cm}$ deep sections. Each drill interval is removed and transferred to an instrument for analysis. An advantage to this approach is that the depth stratigraphy of the hole is preserved (per $10 \mathrm{~cm}$ interval). Since the auger does not have to convey the full depth of material to the surface at once, the auger power and the risk of getting stuck in the hole is substantially reduced. In addition, since the drill is above the hole during the sample analysis (i.e. in its "home" position), the drill temperature and the subsurface temperature are able to equilibrate to the environment, preserving the volatiles.

American Institute of Aeronautics and Astronautics 
The auger passes through the sample delivery mechanism (Fig. 4) which has several functions. It is deployed and pre-loaded on the soil surface prior to drilling operations acting as a stabilizing foot to ensure straight penetration into the soil bed. This approach also isolates drill's Weight on Bit (WOB) from the rest of the spacecraft - it is now reacted through the foot. Such deployment has been successfully used before on Mars Exploration Rover (MER) Rock Abrasion Tool (RAT) and Curiosity Drill. When the auger is retracted, the $10 \mathrm{~cm}$ of sampling flutes, and thus the sample, are contained within this mechanism. Thus both the sample and the volatiles are contained during transfer to the analysis subsystem. Sample transfer is achieved using a passive brush inside the mechanism. The brush forms a worm gear configuration with the auger and hence turns as the auger is rotated past. During sample transfer, the auger rotates (causing brush to spin) and also retracts while material falls out through a funnel directed into the sample collection crucibles.

The drill has 4 actuators: Auger (rotation), Percussion, Deployment Z-Stage, and Drill Z-stage. The Auger can rotate at approximately $\quad 200$ revolutions per minute (rpm) and can sustain a peak stall torque of $10 \mathrm{Nm}$. The percussive system is
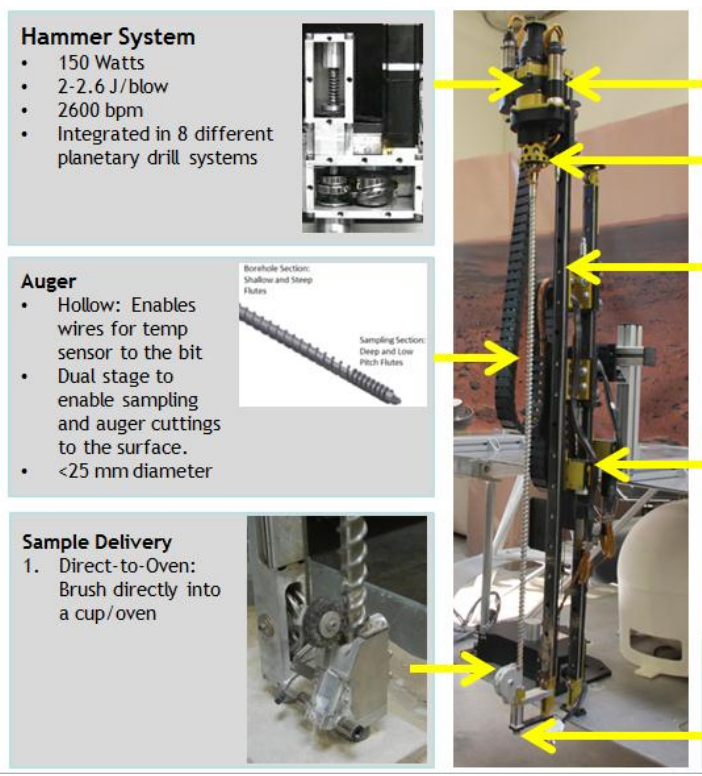

Figure 4: The drill system from Honeybee Robotics.

Rotary System

Power: 150 Watt

Rotation speed: $200 \mathrm{rpm}$

Slipring

- 4 channel

- Can support 1 RTD or 2 Thermocouples

Z-Stage

- Enables auger penetration to $1 \mathrm{~m}$

Pulley based

Load from actuator current

Max force: $500 \mathrm{~N}$ (any direction)

Deployment Stage

- Deploys and preloads drill against ground

Pulley based

Load from actuator current

$40 \mathrm{~cm}$ stroke (depends on rover-ground clearance)

- Max force: $500 \mathrm{~N}$ (any direction)

Bit

Tungsten Carbide

Serrated cutters

Embedded temperature senso

decoupled from the auger rotation and is only engaged when needed (e.g.. when penetrating hard material or during sample transfer step). It can deliver up to $2.6 \mathrm{~J} / \mathrm{blow}$ at 1600 blows per minute. The two $\mathrm{Z}$ stages use dust and vibration tolerant cable-pulley systems and can deliver $500 \mathrm{~N}$ of push/pull force. The Deployment Z-Stage lowers the drill to the ground and typically preloads it with $100 \mathrm{~N}-150 \mathrm{~N}$ (this preload force can be specified in the software based on mission requirements and cannot exceed $500 \mathrm{~N}$ ). The Drill Z-stage provides the penetration force called Weight on Bit (WOB), which is typically software limited to not exceed $75 \%$ of preload force. Since the drilling forces are reacted through the Deployment Z-stage, this WOB limit prevents lifting of the deployment stage.

\section{Sample Capture Mechanisms}

A set of six specialized sample capture mechanisms (SCM) were built to house the soil samples and retain volatiles. A SCM (Fig. 5) consists of a removable sample crucible and a remotely actuated sealing mechanism. The crucibles and the knife edge seals were based on the current RESOLVE reactor design. The critical function of the SCMs was to quickly seal the soil sample after transfer from the drill and maintain a hermetic seal until the crucibles could be removed for analysis (e.g. after the chamber was restored to atmospheric conditions). Thus the seals had to be dust tolerant and a apply sufficient clamping force to prevent loss of volatiles.

The SCM shown in Fig. 5 is in the closed (sealed) position with the removable crucible shown at right. The 18 $\mathrm{mL}(1.9 \mathrm{~cm}$ diameter) crucible was designed to hold a projected $10 \mathrm{~mL}$ of soil. The diameter of the crucible was matched to that of the drill's funnel to minimize soil spillage.

The SCM is a solenoid actuated, spring driven mechanism with a knife edge-to-teflon seal. The removable teflon seal is held in crucible lid which is retained inside SCM's lid assembly, while the mating knife edge is on the flange of the crucible. Both items can be seen in open SCMs in Fig. 5. The spring loaded lid assembly is held open with the solenoid actuated latch. Once the latch is released, the lid assembly snaps down onto the crucible flange with $450 \mathrm{~N}$ (100 lbf) clamping force. The knife edge cuts into the teflon, creating the seal. A four bar linkage ensures that the lid assembly is parallel to the crucible in the clamping position so that the force is evenly distributed (as opposed to a simple hinge, where the portion nearest the pivot would see the most force).

To remove the crucible for analysis, the crucible lid is screwed down onto the crucible flange then unscrewed from the lid assembly. With the crucible lid affixed to the crucible, the lid assembly is opened and the sealed crucible can be removed. Moisture analysis of the soil involves weighing the filled crucible (to obtain the wet soil mass) then 
heating the crucible to $110^{\circ} \mathrm{C}$ to bake out the moisture. A vent screw in the crucible cap allows the moisture to escape during the bake out process.

It should be noted that there were twelve sample crucibles (one for each data point) and six SCMs. Thus the mechanisms were used twice but crucibles were used just once. In this document the SCMs are labeled 1-6, which is indicative of their position in the mounting bracket (Fig. 5 right). The crucibles (and the samples they contain) are labeled 1-12 and were positioned in the SCMs chronologically. So for example crucible 1 (test 1) and 7 (test 2) were in SCM 1 and crucibles 6 and 12 in SCM 6.
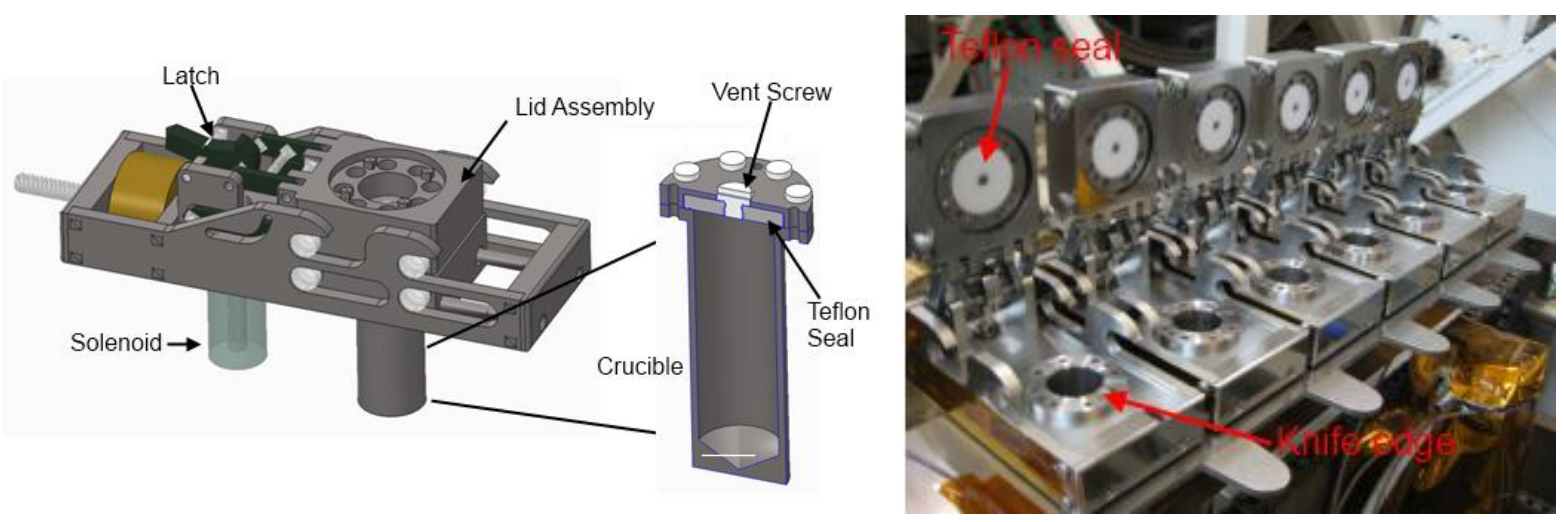

Figure 5: The sample crucible mechanism (SCM) is shown graphically at left. The crucible which holds the soil sample is a $18 \mathrm{ml}$ removable cylinder shown in the blow up. At right, all six SCMs are shown in the mounting bracket. The crucibles are open (unsealed) so that the teflon seal in the crucible lid and the mating knife edge can be seen.

\section{Procedures}

The test matrix is shown in Table 1. Six sampling operations could be accomplished per thermal vacuum test. Thus two tests were performed, each with its own soil bin. Both soil bins were prepared with the same initial soil moisture content (5 wt \%) which is consistent with results from the LCROSS ${ }^{2}$ measurement at the lunar pole. The drill sample depth was also held constant at $40 \mathrm{~cm}$ to $50 \mathrm{~cm}$ depth range for repeatability. Vacuum exposure will cause desiccation of the soil bed, but previous data with this soil bin ${ }^{4,7}$ have shown that the majority of the soil desiccation occurs within the top $20 \mathrm{~cm}$ to $30 \mathrm{~cm}$. Thus, the sampling depth was chosen to avoid the desiccated layer. The two variables in this test series were the temperature of the crucible and the exposure time of the soil in the crucible. In terms of volatile retention, the best results were expected for cold crucibles (< $-50^{\circ} \mathrm{C}$ ) and for immediate sealing of the crucible upon sample transfer. However, test conditions were varied to investigate potential concept of operations on the Moon and sample transfer delays. The conditions used in samples 4,5 , and 6 were intended to represent a potential mission concept of operations. Because the RESOLVE payload will be contained inside a rover, the crucibles may be heated by the surrounding equipment. Therefore these three crucibles were wrapped with kapton heaters to achieve elevated temperatures of $+10{ }^{\circ} \mathrm{C}$. All other crucibles were simply left exposed to the chamber cold wall. Likewise the operation

Table 1: The test matrix.

\begin{tabular}{|l|l|l|l|l|}
\hline $\begin{array}{l}\text { Sample } \\
\text { number }\end{array}$ & $\begin{array}{l}\text { Soil water } \\
\text { content } \\
\text { by weight }\end{array}$ & $\begin{array}{l}\text { Sample } \\
\text { starting } \\
\text { depth, cm }\end{array}$ & $\begin{array}{l}\text { Crucible } \\
\text { Temperature, } \\
{ }^{\circ} \mathbf{C}\end{array}$ & $\begin{array}{l}\text { Time to } \\
\text { seal }\end{array}$ \\
\hline \multicolumn{5}{|c|}{ Test 1 } \\
\hline 1 & $5 \%$ & 40 & $<-50$ & Immediate \\
\hline 2 & $5 \%$ & 40 & $<-50$ & Immediate \\
\hline 3 & $5 \%$ & 40 & $<-50$ & Immediate \\
\hline 4 & $5 \%$ & 40 & 10 & 3 min \\
\hline 5 & $5 \%$ & 40 & 10 & 3 min \\
\hline 6 & $5 \%$ & 40 & 10 & 3 min \\
\hline \multicolumn{5}{|l|}{ Test 2 } \\
\hline 7 & $5 \%$ & 40 & $<-50$ & Immediate \\
\hline 8 & $5 \%$ & 40 & $<-50$ & Immediate \\
\hline 9 & $5 \%$ & 40 & $<-50$ & Immediate \\
\hline 10 & $5 \%$ & 40 & $<-50$ & Immediate \\
\hline 11 & $5 \%$ & 40 & $<-50$ & Immediate \\
\hline 12 & $5 \%$ & 40 & $<-50$ & Immediate \\
\hline
\end{tabular}


of the sealing mechanism on the RESOLVE reactor has a potential 3 min actuation delay. These variables were ultimately fixed in Test 2 due to difficulties sealing the SCMs during Test 1.

\section{A. Soil Bin Preparation}

Preparation of the soil bins was performed following the procedures described in Reference 4 . Both bins were prepared with a uniform water content of 5\% by mass. The NU-LHT-3M lunar regolith simulant was doped with water in $25 \mathrm{~kg}$ batches using a cement mixer and a water sprayer to achieve good mixing. Samples were removed from each batch to verify moisture content according to ASTM $2216^{8}$. The soil bin was filled and compacted one batch at a time. Compaction was performed according to ASTM $4253^{9}$ using a vibration table and a $68 \mathrm{~kg}(150 \mathrm{lb})$ surcharge weight. The density achieved using this procedure at the $5 \mathrm{wt} \%$ water content was $1.47 \mathrm{~g} / \mathrm{cm}^{3}$. Thermocouples were embedded in the soil as the bin was filled. The soil was then covered with a tight fitting lid (to prevent volatiles loss), placed in a upright freezer, and chilled to $-20^{\circ} \mathrm{C}$ prior to transport to the VF13 chamber. The lid remained on the soil until just before the vacuum chamber was closed.

\section{B. Facility operations}

Once the soil bin was positioned and secured inside VF13, the $\mathrm{LN}_{2}$ cooling loops were clamped on. The loops, which remain in the facility to avoid breaking the fluid connection, were clam-shelled around the soil bin and wrapped in an multi-layer insulation blanket. The translation stage, with the drill hardware attached, was then lifted into the chamber and mounted above the soil bin. The soil surface was exposed immediately prior to installation of the cold wall. The VF13 lid was then installed and the chamber was purged with $\mathrm{GN}_{2}$ to reduce the atmospheric moisture in the chamber. There are 4 vacuum pumps on VF13 to support a range of pressure regimes and pumping rates.

Regolith simulant has a tendency to violently off-gas (in the form of soil eruptions or spouts) when the pressure decay rate is high. This ruins the compaction of the soil bed, so slower pump rates are used to mitigate the disturbances. The risk of this occurring is primarily during the rough-pump regime: atmospheric pressure down to 1 Torr. The venturi pump has been very successful in avoiding disturbances and was used from atmospheric pressure to 100 Torr. (The pump dead heads at 30 Torr after $4 \mathrm{hrs,} \mathrm{but} \mathrm{reaches} 100$ Torr in $2 \mathrm{hrs}$ ). A displacement pump was then used to reach 0.75 Torr. $\mathrm{GN}_{2}$ was manually bled into the chamber and the pump line to reduce the pump rate. This is the period of highest risk for soil eruptions, and requires close attention for approximately $2 \mathrm{hrs}$.

The liquid nitrogen cooling to both the cold wall and the soil bin was activated when the chamber reached 10 Torr. The cooled surfaces will act as an additional pump, but at this pressure the additional pump rate has low impact on the soil eruptions. The lower pressure also minimizes frost build up in the chamber. The turbo molecular pump was activated at 0.75 Torr . This pump maintains the chamber at $10^{-5}$ Torr, and can be left unattended. It took at least 48 hours for the soil to chill to temperatures in the $-130^{\circ} \mathrm{C}$ range. Just before the test started, the cryogenic (cryo) pump was activated in parallel with the turbo pump to reduce the pressure to $10^{-6}$ Torr.

In addition to real time pressure and temperature measurements, a Residual Gas Analyzer (RGA) was used as an indicator of primary gas species in the chamber, including what species are off-gassing during drilling. RGA can be used at pressures $<10^{-4}$ Torr. Hardware operations and soil condition were monitored and recorded using four internally-mounted video cameras connected to a video monitor.

The turbo and cryo pumps remained active during drilling operations, as did the soil bin cooling system. However, 2 hours before the test, the cold wall cooling system was shut down to allow hardware to warm. This was done to better mimic the radiative thermal environment inside the rover during the actual mission. Once all sample delivery and sealing operations were completed, the cooling and pumping systems were shut down. For test \#2, the chamber was back filled with $\mathrm{GN}_{2}$ immediately following the test. The chamber remained closed until the residual $\mathrm{LN}_{2}$ in the cooling lines has boiled off (typically an overnight).

\section{Drilling and Sample transfer}

The test matrix in Table 1 required 6 drill holes per test. Fig. 6 shows the hole patterns from the two tests. The

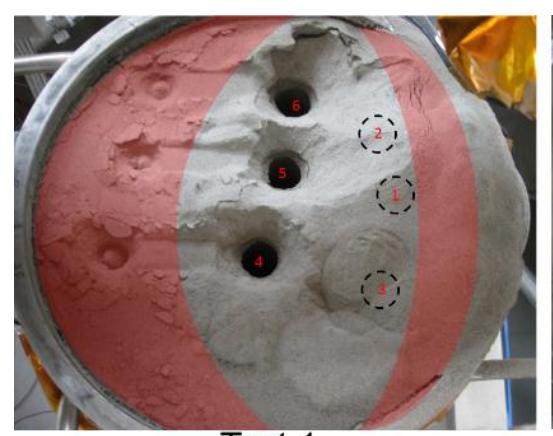

Test 1

Figure 6: The drill hole pattern from the two tests. Approximate hole locations are shown for those that were backfilled. Holes are labeled according to sample (crucible) number. 
areas in red in the first image indicate the regions of the soil bed that could not be accessed due to hardware interferences.

At the onset of the test, the drill was first lowered near the soil surface using the Deployment Z-stage so that the bit was visible in the camera view. The translation table was then manually operated with aid of the video cameras to selected drill location. Once the drill foot was preloaded against the surface, the drilling sequence began. As mentioned earlier, the drill used the bite sampling approach, whereby samples were captured every $10 \mathrm{~cm}$. Since the purpose of these tests was to capture and deliver a sample between $40 \mathrm{~cm}$ and $50 \mathrm{~cm}$ depth, the first four $10 \mathrm{~cm}$ bites were discarded onto the surface. As the tests progressed, a faster "direct drilling" approach was investigated; drilling to $40 \mathrm{~cm}$ depth in a single operation, pulling the drill out to clean off the sample bit, followed by sample capture between $40 \mathrm{~cm}$ and $50 \mathrm{~cm}$ depth. The Z-stage current was used to sense the location of the bottom of the hole. In some cases, another drill/clean sequence was necessary due to fallback of the soil cuttings into the hole.

Once the sample was captured and retracted from the hole, the auger was positioned over an open sample crucible using the translation table. The delivery mechanism was lowered so that the funnel was $3 \mathrm{~mm}$ above the crucible to minimize spillage and potential contamination of the seal. The drill made 4 passes past the brush to dispense the soil into the crucible and clean the auger. After sample transfer, the drill was moved to safe distance to provide clearance and the SCM was triggered to close and hermetically seal the crucible. Table 2 shows the times of the soil dispensing process where "dispense time" is period that the auger was actively brushing material into the crucible, "close time" is the time between the end of dispensing step until the crucible lid was closed, and "exposure time" is the sum of previous two time intervals.

Despite efforts, contamination of the SCMs was a frequent issue, especially during Test 1 . While lowering the funnel close to the crucible minimized seal contamination from the sample delivery mechanism, this did not protect against residual soil falling from the upper portion of auger. In some cases enough material fell onto the seals such that it covered the knife edge (Fig. 7a). The SCM was able to close, but did not seal. In other cases there was material built up on the sides of the SCMs which jammed the rollers on the 4 bar-linkage mechanism. In those cases the SCMs did not close at all; the force of the spring was insufficient to overcome the added friction. Only two of the six SCMs in Test 1 successfully closed and sealed. In Test 2, two mitigation techniques were employed (Fig. 7b): the rollers were protected with Kapton tape and a sheet metal guard was placed above the delivery mechanism to divert falling material away from the SCMs. All of the SCMs in Test 2 closed, though two did not seal properly, indicating that the current mitigation techniques would need to be further refined.

In both tests, the fill order of the crucibles was altered to increase the likelihood of
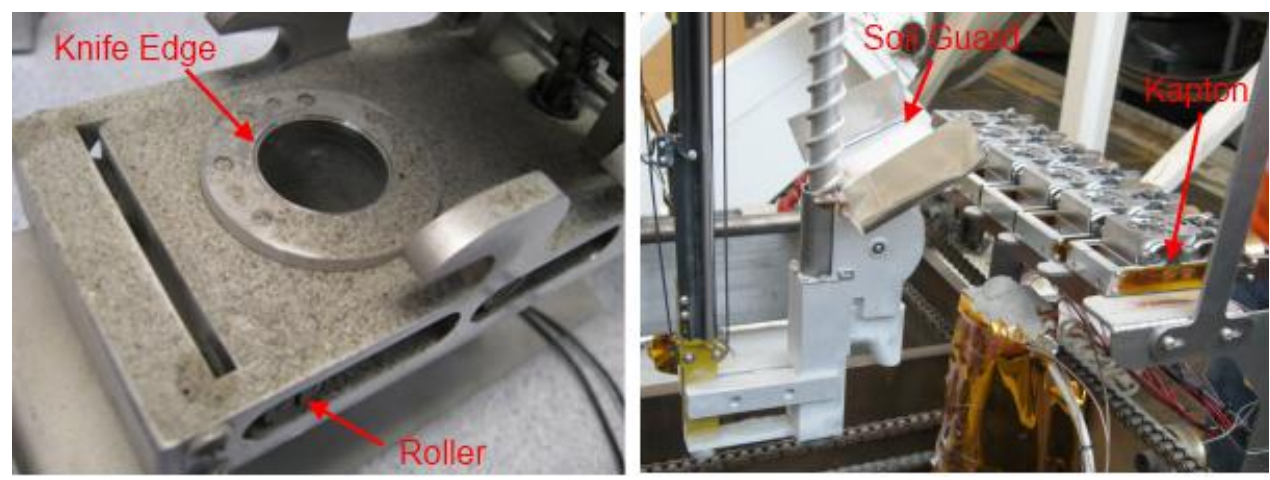

Figure 7: At left, the sample collection mechanism after Test 1 . Soil falling from the upper portion of the auger contaminated the knife edge seal. At right, the mitigation techniques used in Test 2 including the soil guard and kapton tape over the rollers.

American Institute of Aeronautics and Astronautics 
success. Recall that the crucibles in SCMs 4, 5, and 6 were fitted with heaters (though they remained unused in Test 2). The procedure was to wait until the crucibles in SCMs 1-3 were filled before activating the heaters on SCMs 4-6. This way the first crucibles would meet the target temperature condition of $<-50^{\circ} \mathrm{C}$ via cold wall exposure alone. The first three crucibles in both tests (SCMs 1-3) were filled in chronological order. The final three crucibles were filled in reverse order: SCMs 6, 5, then 4 . The SCMs were very close together so cross contamination when filling the neighboring crucible was a concern. Thus, SCM 6 was the least likely heated crucible to be contaminated, so would stand the best chance of sealing.

\section{Soil Sample Analysis}

Once the test was complete, all crucibles were removed and the soil was analyzed for moisture content. The sealed crucibles were cleaned using isopropyl alcohol. The Kapton heaters were removed from the heated crucibles and the adhesive was cleaned off so as not to influence the weight. Each crucible was then weighed to obtain the soil wet mass $\left(\mathrm{m}_{\text {wet }}\right)$. The vent screw in the top of the crucible was then removed, and the crucible was immediately weighed again. A weight gain indicated the addition of atmospheric air to the crucible. Since the crucible was sealed at vacuum conditions, a weight gain meant the hermetic seal was good. All crucibles were then placed in a convection oven and allowed to bake overnight at $110{ }^{\circ} \mathrm{C}$, according to ASTM $2216^{8}$. The hot crucibles were removed from the oven, immediately sealed with the vent screw, allowed to cool to room temperature, and weighed to obtain the soil dry mass $\left(\mathrm{m}_{\mathrm{dry}}\right)$. To verify the samples were fully dry, the crucibles were returned to the oven for further bake out. However, in all cases the resulting mass change was negligible. The lids were then removed and the sample depth within the crucible was measured to determine soil volume and density. Once seals were fully inspected and imaged, the crucibles were emptied, thoroughly cleaned, and then weighed again $\left(\mathrm{m}_{\text {empty }}\right)$. The soil moisture was then calculated according to Eqn. (1).

$$
w t \%_{\text {water }}=\left(\frac{m_{w e t}-m_{\text {dry }}}{m_{\text {dry }}-m_{\text {empty }}}\right) * 100
$$

The moisture content of the soil remaining in the bin was also analyzed after the test. This 'post mortem' was performed on the thawed soil bed at room (laboratory) conditions. Soil samples were removed from the bin at progressive depth increments using a commercial core drill bit $(3.8 \mathrm{~cm}$ diameter, $3.8 \mathrm{~cm}$ cut length). Samples were all taken from the virgin (undrilled) area of the bin. Two holes were drilled down to $50 \mathrm{~cm}$, the maximum reach of the arbor, and samples removed every $3.8 \mathrm{~cm}$. All the material in the top $50 \mathrm{~cm}$ was then emptied from the bin, and two more holes drilled from $50 \mathrm{~cm}$ to $90 \mathrm{~cm}$ depth in the same manner. Each sample was transferred to glass sample jar, sealed, and analyzed for water content using the same method as with the crucible samples. The results are shown in Fig. 8.

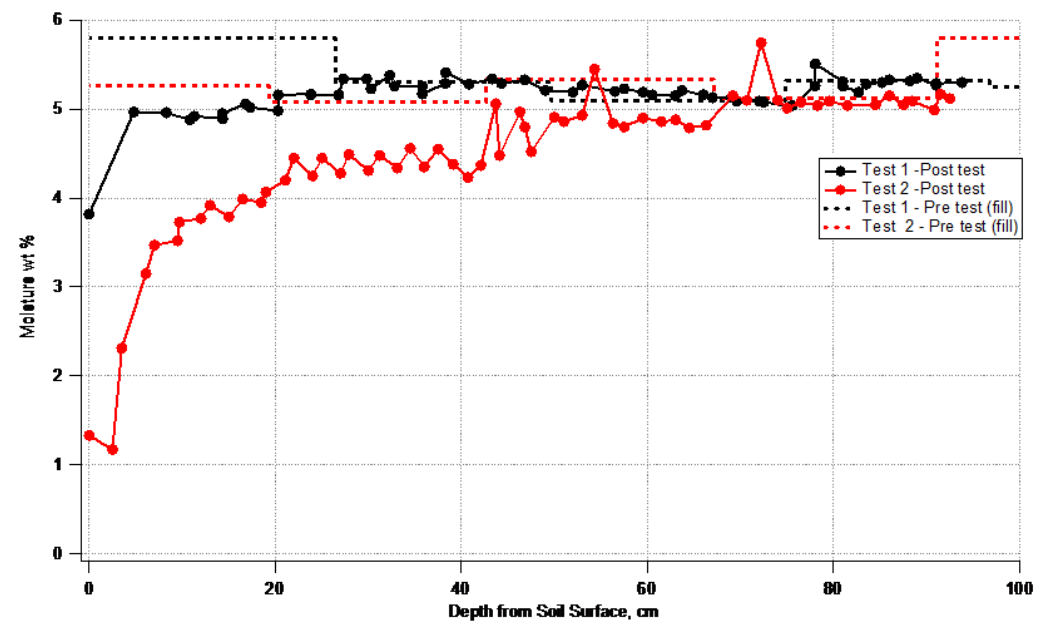

Figure 8: The soil moisture content of the soil bin as a function of depth is shown. The dotted line represents the pre-test batch fill, and the solid line is the post-test distribution after bin had thawed.

\section{Results and Discussion}

The test results are summarized in Table 3. The first column lists general test conditions. In the second column, the pre-test moisture content was based on the as-filled soil batches while the post-test moisture was based on samples removed from the thawed soil bin (Fig.8). Both numbers come from samples captured at the depth of $40 \mathrm{~cm}$. The crucible temperatures were measured by a thermocouple placed on the outer surface of the crucibles. The drill bit and the cold wall temperatures at the time of sample acquisition are also shown. The water wt $\%$ column indicates the water content of the soil in each crucible. The uncertainty in the moisture measurements is $\pm 0.4 \mathrm{wt} \%$. Multiple samples taken from the same soil batch can result in a $\pm 0.3 \mathrm{wt} \%$ moisture variation alone ${ }^{7}$, even with thorough mixing

American Institute of Aeronautics and Astronautics 
techniques when doping the soil. The measurements in bold are considered to be good data points. The final column indicates the percent of water lost, assuming the post-test moisture content represented the available water in the bed.

As discussed previously, half of the test points were invalid due to poor crucible seals. In two cases of poor sealing (crucibles 7 and 11) the sample preserved large fraction of water. Hence despite poor seal, volatiles were retained. Two samples (crucibles 8 and 9) could not be analyzed due to insufficient sample mass delivered from the drill. This event was investigated and sample delivery failure attributed to the passive brush being jammed full of material. Normally, the percussive system is engaged during sample delivery to promote material flow, but was disengaged in these tests to prevent premature closure of crucibles due to vibrations in the system. The jam was noticed during drilling for sample 12, so percussion was engaged with the auger near the soil surface to clear it. Therefore, only in four cases (crucibles 3,6,10,12) did the tests perform according to requirements, but in six cases (crucibles 3, 6, 7, $10,11,12)$ a large fraction of water was preserved.

Table 3: The data summary of all the soil samples.

\begin{tabular}{|c|c|c|c|c|c|c|c|c|c|c|c|}
\hline & \begin{tabular}{|c|} 
Pre- \& \\
Post- Test \\
water \\
@depth, \\
$\%$ \\
\end{tabular} & Crucible & $\begin{array}{l}\text { Wet soil } \\
\text { mass, g }\end{array}$ & $\begin{array}{l}\text { Dry soil } \\
\text { mass, } \mathrm{g}\end{array}$ & $\begin{array}{c}\text { Dry Soil } \\
\text { Volume, cc }\end{array}$ & $\begin{array}{c}\text { Crucible } \\
\text { temp @ } \\
\text { transfer, }{ }^{\circ} \mathrm{C}\end{array}$ & Water \% & Status & Bit temp, C & $\begin{array}{l}\text { Thermal } \\
\text { shroud } \\
\text { Temp, C }\end{array}$ & $\begin{array}{c}\% \text { available } \\
\text { water lost } \\
\text { during } \\
\text { transfer }\end{array}$ \\
\hline \multirow{6}{*}{ 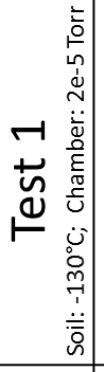 } & \multirow{6}{*}{ 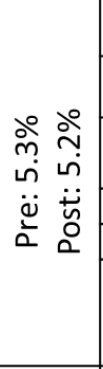 } & 1 & 19.15 & 19.12 & 13.27 & -80 & $0.2 \%$ & Close, bad seal & -73 & -53 & $95.5 \%$ \\
\hline & & 2 & 18.76 & 18.72 & 13.05 & -75 & $0.2 \%$ & Close, bad seal & -70 & -43 & $95.6 \%$ \\
\hline & & 3 & 16.80 & 16.19 & 13.05 & $\sim-70$ & $3.8 \%$ & $\begin{array}{l}\text { Late Close, good } \\
\text { seal }\end{array}$ & -69 & -34 & $26.3 \%$ \\
\hline & & 4 & 4.8 & na & 2.70 & 68 & na & No Close & -70 & -13 & na \\
\hline & & 5 & 4.2 & na & 2.70 & 58 & na & No Close & -67 & $?$ & na \\
\hline & & 6 & 10.85 & 10.55 & 5.85 & 10 & $3.7 \%$ & $\begin{array}{l}\text { intentional 3min } \\
\text { close delay }\end{array}$ & -64 & -23 & $29.8 \%$ \\
\hline \multirow{6}{*}{ N } & \multirow{6}{*}{ 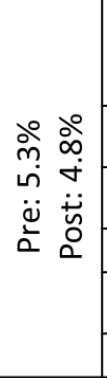 } & 7 & 18.50 & 17.78 & 12.60 & -80 & $4.0 \%$ & $\begin{array}{c}\text { Late Close, Soil } \\
\text { overflow= bad/no } \\
\text { seal }\end{array}$ & -69 & -78 & $15.8 \%$ \\
\hline & & 8 & 0.13 & $0.14^{*}$ & na & -76 & na & Negligible sample & -65.9 & -58 & na \\
\hline & & 9 & 0.32 & $0.33^{*}$ & na & -73 & na & Negligible sample & -63 & -44 & na \\
\hline & & 10 & 6.22 & 6.07 & 4.50 & -55 & $2.6 \%$ & & -60.2 & -20 & $46.8 \%$ \\
\hline & & 11 & 16.05 & 15.59 & 10.12 & -61 & $2.9 \%$ & Close, bad seal & -61.6 & -26 & $38.4 \%$ \\
\hline & & 12 & 16.12 & 15.54 & 10.12 & -65 & $3.7 \%$ & & -61.2 & -34 & $22.7 \%$ \\
\hline
\end{tabular}

\section{A. Moisture content}

The four good samples: $3,6,10,12$, lost an average of $30 \%$ of their potential water during drilling and transfer (Table 3). However the range was between $22 \%$ and $47 \%$. Variables that could impact the water loss include: crucible temperature, exposure time, environmental pressure, environmental (cold wall) temperature, quantity of sample (mass, volume), and drill bit temperature. The fundamental question is when the majority of volatiles would release: during drilling, while on the auger flights, while falling in to the crucible, or while the soil is at rest in the exposed crucible. Which of these processes has the greatest impact on water retention?

Figure 9 shows water loss plotted against several potential factors. In these plots, data from samples 7 and 11 are included. Even though neither crucible sealed properly, both samples showed considerable water retention. Thus they are included, but marked as questionable. In Fig. 9a, the abscissa is the auger bit temperature. The temperature of the bit for all tests is within $-70^{\circ} \mathrm{C}$ to $-60^{\circ} \mathrm{C}$, and while the warmest bit temperature did result in the largest water loss, the scatter in the data does not support a clear trend. Therefore, it is unlikely that the drilling operation alone was a strong contributor to volatiles loss.

Figure $9 \mathrm{~b}$ shows the water loss as a function of sample quantity (wet mass of the soil). Crucible 7 did not fully seal due to overfilling of the crucible (there was more sample on the auger than expected) but had the highest water retention of any sample. It also seems to follow the trend of the four 'good' samples. In the soil bin itself, desiccation from vacuum exposure is primarily restricted to the top $25 \%$ of soil bed (Fig. 8 and Ref. 2) while the material underneath retains tends to retain moisture. This profile has been consistent across previous test programs where the

American Institute of Aeronautics and Astronautics 
soil exposure times range between 50 and $150 \mathrm{hrs,} \mathrm{suggesting} \mathrm{that} \mathrm{a} \mathrm{dry} \mathrm{surface} \mathrm{layer} \mathrm{hinders} \mathrm{moisture} \mathrm{loss} \mathrm{from} \mathrm{the}$ deeper soil. A well filled crucible may result in a similar profile, driving the average moisture content of the crucible up. For a shallower fill, the soil would be more exposed and water more able to diffuse up and out. Crucible 11 may be an example of this since it has a similar soil amount as crucibles 3 and 12, yet shows a significantly higher water loss due to the poor seal. However, it is difficult to verify this. The soil is only at rest in the crucible for <10min minutes (Table 2) before it is sealed. It is unknown how quickly the desiccation layer develops since soil moisture cannot currently be monitored in real time.

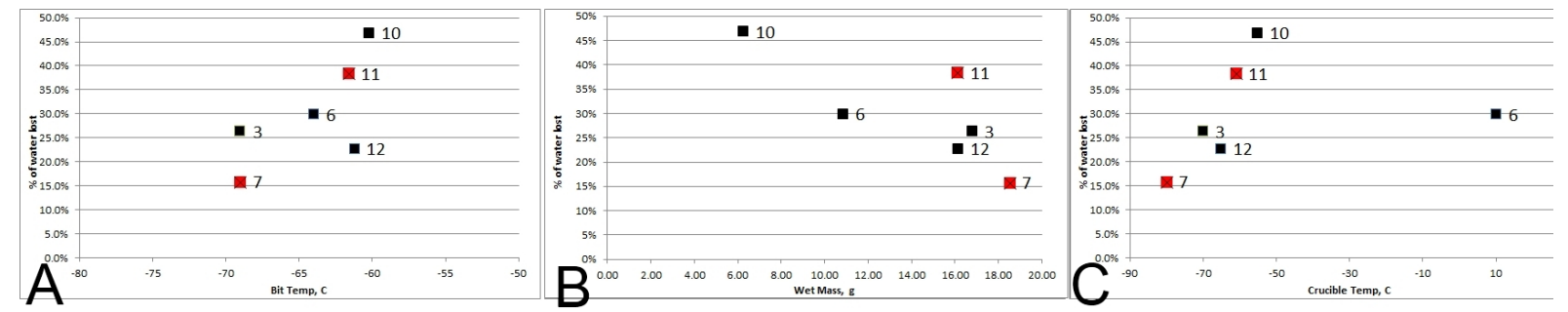

Figure 9: The amount of water lost for the accepted test point as a function of (a) auger bit temperature (b) soil quantity and (c) crucible temperature.

Similarly, Fig. 9c shows water loss as a function of crucible temperature. If exposure to the crucible itself played a significant role in water loss, there should be a clear trend here. Indeed there is, with the exception of crucible 6, which was intentionally heated. This sample should have the highest water loss, but it does not. Since this is the only data point at a significantly higher temperature, it is hard to draw definitive conclusions. Crucibles 4 and 5 were also heated, but the control thermocouple delaminated so their temperatures were driven well above the target of $10^{\circ} \mathrm{C}$. The SCMs in both failed to close, so the effect of the higher crucible temperature on the moisture content could not be quantified. However, visible observation during the filling of crucible 5 showed soil puffing out, presumably due to flash volatilization of water. This is supported by the RGA data (Fig. 10) which shows a clear water peak during the fill process. Presumably a higher water loss versus crucible temperature would have been evident had soil data been available. But the results in Fig. 9c are not conclusive.

However the trend that is apparent in the unheated crucibles in Fig 9c is also reflected in Fig 11, which shows water loss plotted against ambient (cold wall) temperature. The unheated crucible temperatures follow the ambient temperature. Looking at the four good samples, the correlation seems somewhat questionable: the temperature difference between samples 6 and 10 is only $3^{\circ} \mathrm{C}$, yet the water loss is over $15 \%$ different. However, including sample 11 supports this trend. Including sample 7 , with the lowest ambient temperature, changes the curve significantly. If sample 7 can be believed, it suggests that there is rapid increase in water loss in the $20^{\circ} \mathrm{C}$ to $-30^{\circ} \mathrm{C}$ range (where all the other points lay). This is

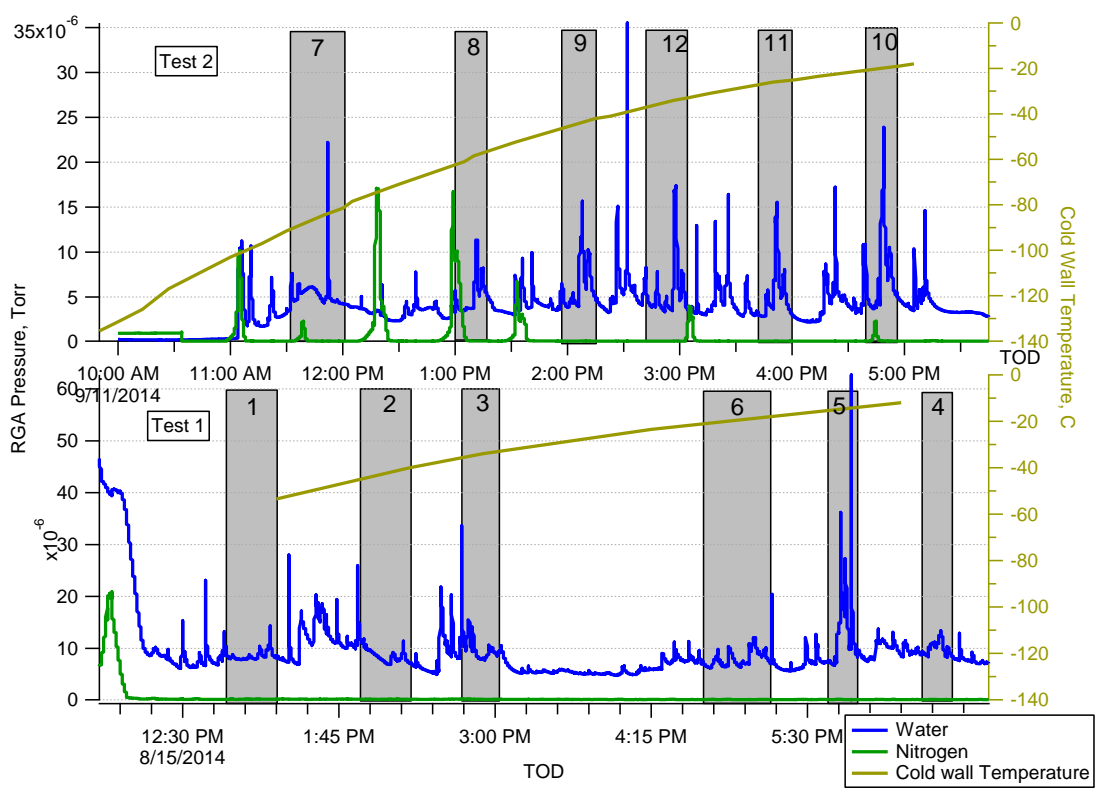

Figure 10: The pressure results from the residual gas analyzer (RGA) is show for the two primary gas constituents. The grey regions indicate the period in which the soil is being transferred into the crucibles indicated. The cold wall temperature is shown corresponding to the right axis.

supported by the sublimation rate data published in Ref. 10, which is plotted on the right ordinance. The sublimation rate does significantly increase in this temperature range in manner that correlates quite well with the measured water

American Institute of Aeronautics and Astronautics 
losses. These published sublimation rates were for planar ice water, therefore would likely over-predict the amount of water loss for this application (where water is adsorbed to soil particles). However, the trend appears to be valid.

The RGA was used during all the tests to indicate increased off gassing. Figure 10 shows the two primary species, water and nitrogen, during drilling and soil transfer operations. Chamber pressure fluctuations were observed throughout the test and were related to cold wall operation. The nitrogen peaks, particularly apparent in test 2 , indicate that these fluctuations are likely a result of a small leak. The cold wall was also deactivated during drilling operations and was warming during the period shown in Fig. 10. Hence some of the fluctuations may be due to off gassing and re-condensing of molecules on the cold wall surface. For most crucible transfers it is not possible to distinguish soil volatilization with these chamber fluctuations.

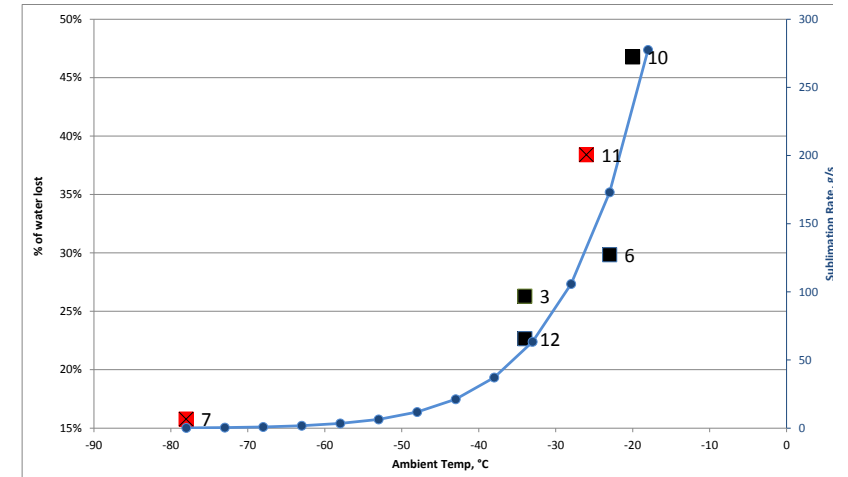

Figure 11: The amount of water lost as a function of ambient temperature, with sublimation rate ${ }^{10}$ overlaid.

\section{B. Drill results}

The Lunar Prospecting Drill performed well at thermal vacuum conditions. Figure 12 shows a sample of data from the first hole (sample \#1 in Test 1). The left plot shows Bit Position (depth of the drill) and the Bit Temperature as a function of time. That plot also clearly illustrates the bite routine - the depth of hole progressively increased in $10 \mathrm{~cm}$ intervals until it reached $500 \mathrm{~mm}$. The drill bit temperature showed an overall decrease as it was exposed to the cold soil. Temperature rose briefly during active drilling, but only a few degrees. Even when using the direct drilling this rise was $<10^{\circ} \mathrm{C}$. Therefore, frictional heating of the auger (which could cause volatilization) does not appear to be a substantial. This is supported by the plot on the right, which shows Net Power (i.e. power required to drill, not including mechanical losses in actuators), Bit Position, and Weight on Bit as a function of time. The drill Net Power - i.e. power required to drill and transport cuttings - was less than 30 Watt. The Net Power therefore represents heat input into the formation. The Total Power takes into account mechanical and electrical losses in the actuators and gears and it is on average $30 \%$ to $40 \%$ greater than the Net Power. The WOB, which is always a critical parameter in low gravity environments, was also low: at or below 30 N. Percussion was rarely needed, which reduced drilling energy.

The average time for each $10 \mathrm{~cm}$ bite was approximately 10 minutes, 2 minutes of which was actual drilling. The entire operation of drilling to $50 \mathrm{~cm}$, capture, and delivery of sample was approximately 50 min. Operational time of drilling and particularly sample delivery was not optimized for the Resource Prospecting system prior to these tests.
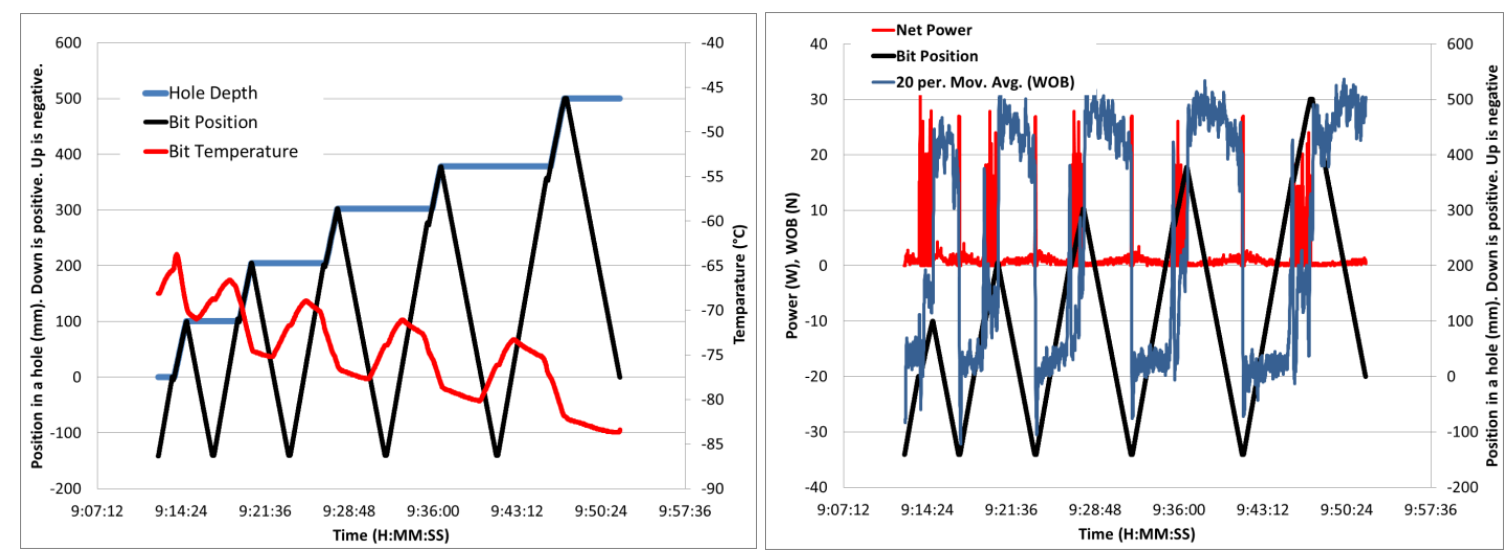

Figure 12: Drilling data from hole (sample) \#1.

The auger was also successful in capturing and transferring the soil samples (Table 3). In all except for 2 tests, a sample ranging in mass from $4 \mathrm{~g}$ to $19 \mathrm{~g}$ was successfully transferred to the crucible. The two failed sample delivery tests are attributed to brush packing up with cuttings, which was subsequently solved by engaging percussion. In 7 of the 12 tests, the samples masses were consistently above $10 \mathrm{~g}$, which was set as the minimum target for the tests. Six of those were over $15 \mathrm{~g}$. However, as can be seen, there was some inconstancy in the mass of sample delivered. In the case of \#7, the sample overfilled such that the crucible did not close properly. To mitigate this risk of overfilling, the

American Institute of Aeronautics and Astronautics 
auger delivery stroke (portion of the auger that was brushed off) was therefore reduced. It is clear, however, that additional work needs to be performed in fine tuning delivery system to result in more consistent and repeatable fills.

At the end of test 2, one additional hole was drilled to study the impact of a "loss of power during drilling" scenario. Such scenario may occur on the Moon and hence needed to be investigated. There are at least two risk areas that would be affected by loss of power. First, when drilling in ice or icy soil, the act of drilling can potentially generate enough heat to create melt around the auger. If the drilling operation stops, this melt could re-freeze, trapping the auger in the hole. Second, rotating the auger in a hole also ensures that the cuttings are continuously being removed, preventing the auger from jamming or choking. During the test the auger was left in a hole at a depth of $60 \mathrm{~cm}$ without rotating or percussing. After a 45 minute period the drill was successfully rotated again and pulled out of the ground without any problems. During retraction, both the auger torque and WOB remained at or below levels seen in the other holes during the retraction step.

\section{Conclusion}

Water is known to exist in the lunar polar subsurface and can be a valuable resource for future exploration missions. However, little is known regarding the depth and distribution of the water as only remote measurements are available. The RESOLVE science package, as part of the Resource Prospector mission, aims to identify and quantify this lunar resource. While past laboratory and field demonstration of the RESOVLE hardware have taken strides to advance flight readiness, relevant environmental testing is needed to make the next steps. Given that the primary goal is to quantify water, it is important to understand how to accurately sample and measure this resource. The act of exposing the subsurface regolith alone would cause some degree of volatilization. Understanding the volatile losses during the regolith sampling process (drilling and transfer) is critical to developing hardware and procedures that will mitigate these losses. This was the goal of the thermal vacuum tests discussed in this paper.

A total of 12 sampling holes were drilled into cryogenically frozen NU-LHT-3M lunar regolith simulant doped with $5 \mathrm{wt} \%$ water. All tests took place at thermal vacuum conditions (pressures of $10^{-5}$ Torr and ambient temperature between $-80^{\circ} \mathrm{C}$ to $-20^{\circ} \mathrm{C}$ ). The Lunar Prospecting Drill utilized an auger with specialized sampling flutes to capture and then transfer soil samples from a required depth range of $40 \mathrm{~cm}$ to $50 \mathrm{~cm}$. The samples were transferred into a set of crucibles with remotely actuated hermetic sealing mechanisms. Sample analysis occurred post-test following standard ASTM procedures.

Of the 12 samples, four were successfully sealed at vacuum conditions for moisture retention. An additional two did not seal, but retained significant moisture. The four sealed samples lost an average of $30 \%$ of their available water with variability between $22 \%$ and $47 \%$. The variability in the results correlated well with ambient temperature: a higher temperature resulted in greater moisture loss. The trend agreed with the sublimation rate predictions over the same temperature range. Moisture retention also correlated with quantity of sample: a larger amount of material resulted in less water loss. This may be related to the desiccation profile of the soil depth due to vacuum exposure where a dry surface layer hinders moisture loss from the deeper soil. Three samples were dispensed into intentionally heated crucibles since, predicted crucible temperatures within the RP rover could be as high as $+70{ }^{\circ} \mathrm{C}$ due to heating from surrounding electronics. Two crucibles, heated to $58^{\circ} \mathrm{C}$ and $68^{\circ} \mathrm{C}$, did not seal and could not be analyzed. However, soil was observed puffing out of the top of the crucible suggesting rapid volatilization of the water. Further examination is needed to determine an acceptable requirement for crucible temperature. The crucible that was heated to $+10^{\circ} \mathrm{C}$ did not show a significant impact on moisture retention. This may suggest that moisture lost happens primarily while the soil is exposed to the environment (as evidenced by the sublimation rate correlation). Water loss while the material is inside the crucible may play a lesser role, as evidenced by the correlations with sample quantity and crucible temperature.

The error in soil moisture measurements is $0.4 \%$, most of which is based on the variability in multiple moisture measurements from the same well mixed soil batch. With this much variability in a controlled sample it is difficult to draw conclusions about the variability in the thermal vacuum results. More consistent sample delivery would be needed to quantify this effect.

The drill itself worked well in the thermal vacuum environment for this soil condition. The drill power was near $30 \mathrm{~W}$ during drilling. Rotary drilling alone was sufficient for most of the time. Percussion, which triggered autonomously based on drilling telemetry feedback, was activated occasionally. Weight on Bit was generally less than $30 \mathrm{~N}$, with some spikes up to $70 \mathrm{~N}$ when percussion was used. Leaving the drill in a hole for 45 minutes did not cause any drill stuck conditions. Although in 10 of the 12 tests some sample was delivered to crucibles, the actual sample mass varied across a large range. Hence future work would need to focus on fine tuning sample delivery system.

American Institute of Aeronautics and Astronautics 
These tests provide critical input to the RESOLVE project and to the potential concept of operations (Con Ops) for the Resource Prospector mission. The auger capture method for soil sampling has been shown to be a valid approach for lunar-like soil conditions. Operational parameters such as drilling and transfer times, will feed directly into Con Ops plans and guide system design. Successful sample capture and delivery to a containment vessel, similar to those planned for the RESOLVE OVEN, was demonstrated. However, improvements are needed to ensure that a more consistent and repeatable sample quantity is delivery. Likewise, future redesigns must address the soil contamination issues on the crucible seals. The tests indicate an acceptable volatile loss of $<30 \%$ can be achieved for sufficient sample quantities provided that the ambient temperature condition is low. However, heating from the surrounding components within the lunar rover configuration may negatively influence volatile loss. Additional testing will be needed to determine the acceptable initial temperature of the crucibles used by the OVEN to collect the regolith sample.

\section{Acknowledgments}

This work is supported by the Regolith and Environment Science and Oxygen and Lunar Volatile Extraction (RESOLVE) project under the NASA Advanced Exploration Systems (AES) program. The sample crucibles mechanisms were designed by John Trautwein at the Kennedy Space Center.

\section{References}

${ }^{1}$ Feldman, W., S. Maurice, A. B. Binder, B. L. Barraclough, R. C. Elphic and D. J. Lawrence, Fluxes of Fast and Epithermal Neutrons from Lunar Prospector: Evidence for Water Ice at the Lunar Poles, Science 4 September 1998: Vol. 281 no. 5382 pp. 1496-1500, DOI: 10.1126/science.281.5382.1496

${ }^{2}$ Colaprete, A., et al, 2010, “ Detection of Water in the LCROSS Ejecta Plume”, Science, 22, 463-468.

${ }^{3}$ Andrews, D, Coleprete, A., Quinn, J., Chavers, D., and Picard, M., "Introducing the Resource Prospector (RP) Mission," AIAA Space Conference and Exposition, San Diego, CA., AIAA2014-4378

${ }^{4}$ Kleinhenz, J.,2014, Lunar Polar Environmental Testing: Regolith Simulant Conditioning. AIAA SciTech 2014: 52 ${ }^{\text {st }}$ Aerospace Sciences Meeting and Exhibit. American Institute for Aeronautics and Astronautics. AIAA-2014-0689

${ }^{5}$ Zacny, K., G. Paulsen, J. Kleinhenz, B. Mellerowicz, P. Chu , D. Kim, and C. Follet, Development and Testing of a Lunar Prospecting Drill (LPD) to Search for Water-Ice, 14th ASCE International Conference on Engineering, Science, Construction and Operations in Challenging Environments, October 27-29, 2014, St. Louis, MO.

${ }^{6}$ Zacny K., Paulsen G., McKay C.P., Glass B., Davé A., Davila A.F., Marinova M., Mellerowicz B., Heldmann J., Stoker C., Cabrol N., Hedlund M., and Craft J. Reaching $1 \mathrm{~m}$ Deep on Mars: The Icebreaker Drill, Astrobiology. December 2013, 13(12): 1166-1198. doi:10.1089/ast.2013.1038.

${ }^{7}$ Kleinhenz, J.E. and Linne, D., 2013, Preparation of a Frozen Regolith Simulant Bed for ISRU Component Testing in a Vacuum Chamber, 51st Aerospace Sciences Meeting and Exhibit. American Institute for Aeronautics and Astronautics. AIAA-2013-0732. NASA/TM-2013-217833.

${ }^{8}$ ASTM Standard D2216-05, "Standard Test Methods for Laboratory Determination of Water (moisture) Content of Soil and Rock by Mass," ASTM International, West Conshohocken, PA.

${ }^{9}$ ASTM Standard D4253-00, "Standard Test Methods for Maximum Index Density and Unit Weight of Soils Using a Vibratory Table," ASTM International, West Conshohocken, PA.

${ }^{10}$ Andreas, E., New estimates for the sublimation rate for ice on the Moon, Icarus, Volume 186, Issue 1, January 2007, Pages 24-30

American Institute of Aeronautics and Astronautics 